\title{
Research on Relationship between Activities of College Student Organizations and Employability
}

\author{
QI Xiaolin ${ }^{1}$ Xie Lufang ${ }^{2}$ \\ ${ }^{1}$ Wuhan associate professor of Technology and Business University. Specialize in human \\ resource management and career planning education. \\ ${ }^{2}$ sales assistant of Market Department, Hunan Boshike Huayi Environmental Engineering Co., \\ Ltd.
}

Keywords: College student organizations, Employability, Planning factor.

\begin{abstract}
The employability of college students can be nurtured in various ways, and also affected by activities of student organizations in different aspects. This paper studies what influence 13 types of activities of college student organizations have on 10 general capabilities of employability. After a questionnaire survey on 389 members of college student organizations in 15 universities, principal component analysis is introduced to the empirical analysis on sample data. The results show that the activities of student organizations can mainly improve the activeness, interpersonal coordination and communication skills of college students for employability, and the employability can be progressively enhanced in the activities of college student organizations through three categories of factors, i.e. planning, attitude and methodology.
\end{abstract}

\section{Introduction}

Domestic and overseas scholars study competency model building and career planning mostly from the approach of college students' employability to help college students with successful employment and facilitate their career development. With regard to empirical study, few Chinese scholars have studied the influence of college student organizations on competency and career planning. In recent years, some scholars have introduced the term "employ competency" and the theory of competency into the career-related behaviors of college students. For instance, Z.H. Qiao (2007) set up a project with Beijing Planning Office of Social Science to study the employ competency model and evaluation of college students. The activities of college student groups have considerable significance to enhancing the employability of college students in both practical and realistic manner. Based on the activities of student organizations in universities, this paper combines personal capability structure and employability to explore the employability of college students and its influencing factors from the approach of employability, and develops the employability of college students through the activities of student organizations in universities at the stage of career planning and execution.

\section{Research Design}

Sample Selection and Argument Source. This paper generalizes the types of activities arranged by student organizations based on an interview with the college students that have ever taken part in the activities of college student organizations in Wuhan. After a questionnaire survey on the activities of college student organizations in Wuhan and the capability cultivation of college students, the results are analyzed to find out the relationship between activities of student organizations and capability cultivation.

The questionnaire survey covers the universities and colleges in Wuhan. Based on the returned copies, it involves 15 universities and colleges, such as, Wuhan University, Huazhong University of Science and Technology, Central China Normal University, Hubei University of Chinese Medicine, Wuhan University of Science and Technology, Wuchang University of Technology and Wuhan Technology and Business University. Among 450 copies handed out, 433 copies are returned with 389 valid copies. The criterion for validity is the nature of respondent. As this questionnaire survey 
focuses on the college students that have ever taken part in the work or activities of student organizations, those respondents without such experience, i.e. 39 copies, are removed. Moreover, 5 copies are obvious unacceptable as they were carelessly completed within 30s online in a hurry. Eventually, there are 389 valid copies left, including 260 copies from public universities and 129 copies from private universities. Among them, 197 valid copies were completed by males, accounting for $51 \%$ of total, while 192 valid copies were submitted by females, accounting for $49 \%$. In general, this satisfies the requirements for avoiding the influence of gender in the questionnaire survey.

Table 1 Summary of Questionnaire Survey Background Analysis

\begin{tabular}{c|c|c|c|c|c|c}
\hline \multicolumn{2}{c|}{$\begin{array}{c}\text { Distributed and Returned } \\
\text { Questionnaire (copy) }\end{array}$} & \multicolumn{2}{c|}{$\begin{array}{c}\text { Nature of } \\
\text { University }\end{array}$} & \multicolumn{2}{c}{ Gender } \\
\hline Distributed & Returned & Valid & Public & Private & Male & Female \\
\hline 450 & 433 & 389 & 260 & 129 & 197 & 192 \\
- & $96.22 \%$ & $86.44 \%$ & $67 \%$ & $33 \%$ & $51 \%$ & $49 \%$ \\
\hline
\end{tabular}

Methodology. Through the interview with members of college student organizations in Wuhan and the collection of information from teachers and internet, etc., we classify the activities of student organizations into 13 types in terms of participant and organization, i.e. volunteer service, extracurricular interest, speech \& debate, theme communication, competition \& contest, handwork exploration, sports \& bodybuilding, files sorting, paperwork composition, planning \& publicity, staff arrangement and coordination, external liaison, internal training.

Based on the research and analysis conducted by Chen Yong (2012) on the influencing factors of general employability, and our interview with the college students taking part in the activities of student organizations, we utilize capability structure theory and competency theory to select 10 basic capabilities from Beisen competency model as the general capabilities of employability for college students, i.e. learning ability, activeness, interpersonal coordination, independence, teamwork, innovation ability, communication skills, self-improvement, prudence \& carefulness and objective awareness.

The principal component analysis is carried out to analyze the elements of career planning from the approach of capability.

\section{Results}

From the empirical analysis, we gain the following results:

Classification of Ten General Capabilities. Attitude factors are mainly reflected in active attitude toward life and work style. An individual can take different ways to coordinate the resources for an appropriate balance and prevent the conflicts harmful to work; understand what others intend to express and share ideas and feelings with others smoothly; have good team work spirit, make efforts to create a good atmosphere for cooperation, share and cooperate with others voluntarily to facilitate the common development of team and the realization of team objectives.

Planning factors are mainly revealed in voluntary and independent thinking and completion of tasks through voluntary actions. An individual is able to understand work objectives clearly and overcome unnecessary interferences during work; pays attention to self-improvement and self-growth, and achieve progress through effective learning.

Methodological factors mainly include the desire to try new things and the ability to understand and organize the information from new perspectives, so as to gain the new opinions and new methods for improving and promoting work. An individual can effectively identify and constantly pay attention to key aspects affecting the work, and must act prudently to ensure no mistake.

Different Activities Having Different Influences on Factors. Planning factors are noticeably influenced by the activities of extracurricular interest, competition \& contest and sports \& bodybuilding. Methodological factors can be greatly cultivated through the activities of competition 
\& contest and handwork exploration. Attitude factors are further promoted in the activities of volunteer service, extracurricular interest, and external liaison.

Different Measures at Different Stages of Career. The activities of college student organizations can mainly cultivate the capabilities of employability including activeness, interpersonal coordination and communication skills. A career is practically divided into three stages, i.e. goal setting, practice planning, assessment and modification. In these three stages, the planning, methodological and attitude factors play different roles. Planning factors define the scope of goal setting, methodological factors provide the options for practice planning, and attitude factors can balance all kinds of elements in the career, and be employed to assess and modify the actions taken to achieve the set objective of career planning.

\section{Countermeasures and Recommendations}

Based on the above results, career planning can be implemented by improving the platform of college student organization, executing in stages and establishing practical system.

Improving the Platform of College Student Organization for Career Planning Practice. By arranging and taking part in activities of college student organizations, college students can improve their employability. However, it is necessary to first improve the staff mobilization mechanism of college student organizations to cultivate the corresponding capabilities of college students, make the ready for employment and lay a foundation for their career planning. In this way, college student organization, as a practical platform, can be guaranteed based on the stable structure and long-term development of student organization, in order to provide the corresponding facilities for cultivation of college students' capabilities. Also, good application platform will be constructed for the practical education of career planning in universities and colleges through the long-term development planning of college student organizations, so that college student organization will become a practical development base for career planning education in universities and colleges and play a significant role in the environment of talent cultivation in universities and colleges.

Implementing Career Planning through the Platform of College Student Organization. At different stages of career planning, different capabilities of employability will be improved in different activities of college student organizations. Meanwhile, career planning will also promote the improvement and innovation of activities for college student organizations.

First, the practical education of career planning is put forward from the perspective of student organization. The active roles of college student organization should be sufficiently utilized in extracurricular activities to cover the students of all grades and majors by all means, so as to inspire their interest in self-exploration, subjective activeness in occupational exploration, and voluntariness and sense of responsibility in career planning. Second, the specialization of college student organizations will be promoted to provide the specialized trainings for the members of specialized college student organizations, including guided self-education for theoretical knowledge and design experience of practical activities. Then, college student organizations should arrange all kinds of innovative career-related activities on campus for motivating more college students to participate in the practice of career planning and gradually complete own career planning and selection. Third, the information platform of students should be constructed to establish an exclusive consulting platform for students. In other words, efforts are made based on different features of majors to help students learn about the occupations suitable for their majors, and activities are organized to help students experience the switch of role into occupations and better understand the focus of self-development.

Establishing Practical System. To implement the occupational planning and practical activities at all levels under the guidance of college student organizations in an orderly manner, a practical system must be established. The practical system will be able to reflect setting of objectives, decision-making on occupation, follow-up and feedback on employment. The practical system of career education covers not only curricular and extracurricular practical activities, but also on-campus and off-campus practical activities.

On-campus practical activities include: (1) After-class discussion space for career planning 
provides a platform for students that are taking the course of career planning to communicate and discuss with each other. Some games related to the theories of the course are organized to improve the understanding about these theories and motivate students to take the course. (2) On-campus career planning competition, recruitment simulation competition, professional knowledge contest and lecture can be organized to improve students' awareness of planning, and help them determine own objectives through on-campus practical activities.

Off-campus practical activities include: (1) Individual or group internship is arranged for students by inviting enterprise representatives as the judges of competition and interview in the on-campus career-related activities, and creating the opportunity of internship for excellent students. Meanwhile, this can help universities supply the professionals to enterprises in a collective manner and make more students take an internship more suitable for their majors, so as to facilitate the realization of their occupational objectives. (2) Through continuous measurement and evaluation, the career development database of students is established to provide the reference for students intended to change a job and the cases and data for universities in the teaching of the course. Hence, students can delve into the track of own career development from the approach of occupational measurement and evaluation, so as to be well ready for better career development in the future.

\section{References}

[1] C.F. Xiang, Theory and Empirical Study on Competency, Nanjing Normal University, Nanjing, (2003).

[2] S.S. Li, Career Planning and Related Factors in College Students with Graduates, Anhui Medical University, Hefei, (2008).

[3] Y. Chen. Research on Employability and Development Path, Zhejiang University, Hangzhou, (2012).

[4] X.L. Qin, Research on Influence of Student Organizations on Adaptability of College Students to Employment, South-central University for Nationalities, Wuhan, (2009).

[5] S. Zhao. On Restrictions of Individuals and Groups-Analysis on Social Functions of Student Organizations in Universities, Jilin University, Changchun, (2004).

[6] W.S. Chen, Research on Competency Model of Human Resource Management Personnel in Chinese Enterprises. Xiamen University, Xiamen, (2004).

[7] X.D. Chai. Research on Enterprise Education in Universities Based on Implicit Knowledge, East China Normal University, Shanghai, (2010). 